\title{
The Scope of Health Injustice
}

David Bann PhD, Centre for Longitudinal Studies, Department of Social Science, University College London, London, WC1H 0AL, UK david.bann@ucl.ac.uk

Framing avoidable group differences in health as unjust—-that is, as health inequities—is a powerful motivator for funding, research, and policy development. It is therefore important to consider which forms of health difference could or indeed should be considered health inequities. Socioeconomic differences in health are widely judged to be health inequities and there are corresponding well-developed funding, research, and policy agendas. In contrast, differences in health due to two controversial determinants—'intelligence' and genetic propensity to ill health—are not. Both however appear to meet multiple different definitions of health inequity: as with socioeconomic exposures, differences in health due to these factors are largely or entirely outside of individuals' control, with evidence for their (probabilistic) effects on health and social outcomes, and potential amelioration by societal intervention. Similarly, their relative importance is likely specific to context—-time, place, and the health outcome considered. This perspective prompts broader philosophical and evidence-based consideration of which forms of health difference are unjust, and to what degree. To help inform these decisions, continued epidemiological evidence is required across the multiple possible health equity stratifiers: evidence on their magnitude, causal nature, change across time, and potential reduction via intervention.

Key words: health equity, justice, socioeconomic factors, intelligence, genetics 


\section{Background}

Health differences according to socioeconomic position (SEP) are widely framed as being health inequities; monitoring and reducing these health differences are major focuses of national and transnational organisations.(Marmot, 2015; Marmot, Allen, Bell, Bloomer, \& Goldblatt, 2012; The Marmot Review Team, 2010) Awareness of the injustice of SEP differences in health is an important motivator for research funding, the focus of epidemiological investigation, and policy action.(Marmot, 2017) For example, the UK's Prime Minister Theresa May's first speech in 2016 noted as motivation for policy action "the burning injustice that, if you're born poor, you will die on average 9 years earlier than others." (link) It seems intuitive (to most) that SEP differences in health are unjust, and are thus health 'inequities' rather than simply health 'differences'. Considering whether other forms of health difference are inequities is important, give its implications for funding, research, and policy. To explore whether the same definition could or indeed should also be applied to other important risk factors for ill health, let us consider the below thought experiment which includes two controversial determinants of population health.

Individuals in the population are exposed to ' $\mathrm{X}$ ' at birth — they therefore do not choose their exposure, yet it has lasting (probabilistic) causal effects on multiple physical and mental health outcomes which extend across life. It is thus arguably unfair. It is also avoidable, since society can enact policies to prevent these health consequences from occurring, despite exposure to X. It is thus arguably unjust.

Is ' $\mathrm{X}$ '

1) Socioeconomic status/position (SEP)

2) General cognitive capability_-'intelligence' or,

3) Genetic propensity to ill health? 
As implied, there are commonalities between SEP, 'intelligence', and genetic determinants of health; these are potentially obscured when each is the focus of separate sub-disciplines (i.e., social,(Bartley, 2016; Berkman, Kawachi, \& Glymour, 2014) cognitive(Deary \& Batty, 2007) and genetic epidemiology(Kaprio, 2000)). While there are noted and unresolved controversies regarding the relative importance of each of these risk factors on health and social outcomes (which in turn likely differ by disciplinary perspective(Deary \& Johnson, 2010)), for the purpose of this article it is assumed that each generally has independent causal effects on health, whose relative importance is context and outcome specific, and that each are potentially modifiable by the environment (and thus societal change).

Given the above commonalities, are difference in health due to 'intelligence' and genetic propensities also forms of health inequity? According to commonly utilised definitions of health inequity (Table 1), arguably yes in each instance. The most widely used definition of health inequity, seemingly adopted by the World Health Organization,(Organization, 2004) is Whitehead's 1991 definition that inequities are differences in health that are "unnecessary, avoidable, unfair and unjust". Even defining SEP differences in health as health inequity according to this definition requires judgement, particularly in terms of their unfairness and possible modifiability. The authors of this seminal paper noted that it was intended to stimulate debate on these issues rather than forming a canonical definition of health inequity; progress in this area of science is thus furthered by continuing to explore these definitions and their applicability to multiple constructs.

\section{Are genetically-caused differences in health inequities?}

Genetic risk for many complex physical and mental health outcomes is manifest across a normal distribution, quantified by the composite effects of multiple genes which each have probabilistic causal effects (as typically quantified in a polygenic risk score).(Plomin, 2018) The estimated risk on health may be sizable in magnitude; for example, in a UK cohort born in 1992, those in the highest (compared with 
lowest) polygenic risk score deciles for obesity had a 25 -fold increased risk in later adolescence.(Khera et al., 2019) Can these differences be said to be fair? They do not appear so - clearly individuals do not 'choose' their exposure, and in this case the exposure appears to affect obesity risk before the studied population became adults. There is also an emerging literature which suggests that genetic propensities to ill health can have causal effects on socioeconomic outcomes.(Ding, Lehrer, Rosenquist, \& AudrainMcGovern, 2009; Fletcher \& Lehrer, 2009; Howe et al., 2019; Tyrrell et al., 2016) This adds further weight to the suggestion that the consequences of genetic propensities are unfair and — assuming they are modifiable—unjust.(Wester, 2018)

Are differences in health due to genetic susceptibility modifiable? The extent to which a high genetic propensity leads to an actual observed worse health outcome likely depends on the environmental context in which the genes are expressed. In an extreme example, genetic variants which cause increased alcoholism risk(Edenberg \& Foroud, 2013) will not have an observed effect in the absence of alcohol, or arguably smaller effects in societies in which alcohol is a less predominant part of culture. In the behavioural genetics literature, it has been argued that there is no "single" heritability value for a given health outcome-it is simply a value which ranges from 0 to $100 \%$ depending on the environment (both its variability and its relevance for the genetic propensity).(Turkheimer, 2011) For example, where the environment is more obesogenic, obesity-related genes appear to have larger effects.(Brandkvist et al., 2019; Demerath et al., 2013; Rosenquist et al., 2015) As such, the suggestion that 'genetic effects' are inevitable and not modifiable by society may be largely misguided; estimates of genetic effect show what has been the case in the observed sample, not what could be the case in future in a different context.(Plomin, 2018) Whitehead (1991)(Whitehead, 1991) noted that "natural, biological variation" as a cause of health differences are probably not health inequities. Yet this was before insights from genetically-informed studies, and should perhaps now be re-addressed given there is nothing particularly "natural" about how common genetic propensities affect health. Like the role of SEP at birth, exposure to 
a high genetic propensity is outside ones control, and is likely in many instances modifiable by environmental change. It thus appears to meet commonly utilised definitions of health inequity (Table 1).

As the 'DNA Revolution'(Plomin, 2018) continues, and the number of genetically-informed studies grows, consideration of health equity and the role of modifiable societal factors in mediating or moderating genetic 'effects' is likely to be important. This is particularly so given suggestions that prominent thought-leaders in genetic research focus particularly (and arguably erroneously) on the use of genes to make individual-level predictions,(Turkheimer, 2019) or that gene-outcome association cannot be confounded by environmental factors.

\section{Are 'intelligence'-related differences in health inequities?}

The heritability of general cognitive test scores (herein referred to as 'intelligence') is estimated to be high in adulthood, and typically increases with age (eg, up to $60 \%$ in adulthood(Plomin \& Deary, 2015)); there also appears to be evidence for shared genetic aetiology between both 'intelligence' and health outcomes.(Arden et al., 2015; Hagenaars et al., 2016) In addition, it appears to be challenging to directly modify in the long-run via intervention(Protzko, 2015; Sala \& Gobet, 2018)_albeit seemingly possible given evidence for substantial change across time (the Flynn effect)(Bratsberg \& Rogeberg, 2018) and by education attainment.(Ritchie \& Tucker-Drob, 2018) Thus, individuals may have limited control over their own 'intelligence', yet it seemingly affects socioeconomic outcomes (eg, education,(Deary, Strand, Smith, \& Fernandes, 2007) occupational outcomes(Marks, 2013) and income(Zax \& Rees, 2002)) as well as other social outcomes (eg, likelihood of incarceration(Ttofi et al., 2016) and marital breakdown(Aspara, Wittkowski, \& Luo, 2018)). That 'intelligence' is important for socioeconomic outcomes is supported by multiple study designs, including longitudinal observational studies,(Strenze, 2007) twin studies,(Plomin \& Deary, 2015) and those which utilise the random assortment of genes as genetic instruments.(Davies et al., 2019) Given further anticipated causal effects on a range of multiple 
physical and mental health outcomes,(Batty, Deary, \& Gottfredson, 2007; Deary \& Johnson, 2010) these differences appear neither fair nor just. This is particularly so where estimated exposure effects are found to persist from childhood.(Batty et al., 2007; Calvin et al., 2017) These differences are potentially modifiable in the sense that they are all mediated through society which rewards - to varying degrees across time — higher 'intelligence'. Take for example obesity—in the context of an obesogenic environment, default food options are likely to be high calorie and imbalanced.(Radnitz et al., 2013) A repeated finding in the epidemiological literature is that low 'intelligence' test scores appear to predict obesity or weight gain risk.(Chandola, Deary, Blane, \& Batty, 2006; Lawlor, Clark, Smith, \& Leon, 2006; Rosenblad, Nilsson, \& Leppert, 2012; E. Smith, Hay, Campbell, \& Trollor, 2011; Wraw, Deary, Der, \& Gale, 2018) 'Intelligence' may affect individuals' choices within the obesogenic environment—indirect effects may operate through education and corresponding disposable income, enabling the purchasing of more expensive lower calorie and more varied items. Direct effects might operate through higher 'intelligence' increasing the likelihood of healthy options being identified and actioned (e.g., cooking with multiple low-cost vegetables). Where the food environment is modified, the default may be lower calorie options - 'intelligence'-related inequities in weight gain would be expected to narrow in response. Narrowing of these differences may also occur by intervening on the mediators-for example education attainment.(Chandola et al., 2006; Lawlor et al., 2006) These two hypothetical policy responsesmodifying the obesogenic environment and improving education — are similar to those which would be envisaged if the risk factor of interest was socioeconomic in nature. The controversial role of 'intelligence' on health outcomes appears less controversial when seen in this framework, even where a causal role of 'intelligence' is not fully mediated by adult socioeconomic factors. Framing health differences as inequities may help to shift focus from individual blame to how the environment should be modified in order to improve population health, accounting for individual differences in exposure to socioeconomic, 'intelligence', and genetic risk factors. Such an approach is consistent with the public health literature's focus on the potential utility of up-stream interventions, (Lorenc, Petticrew, Welch, \& 
Tugwell, 2013) or those which require minimal individual agency;(Adams, Mytton, White, \& Monsivais, 2016) and with the behavioural economics literature which focuses on targeting non-conscious processes to improve population health.(Downs \& Loewenstein, 2011) Finally, this framing may also help to encourage a broader group of investigators to investigate the potential importance of 'intelligence' and related exposures, rather than those with particularly enshrined views about its causal importance and implied inevitability of effects on important life outcomes.

\section{Should differences in 'intelligence' or genetic propensity be considered health inequities?}

There are, of course, important broader considerations in deciding whether such differences in health should (rather than could) be considered forms of health inequity. One notable concern is the potential for inadvertent adverse consequences_-particularly those which may result in stigmatisation or discrimination. Wolf (Wolff, 1998, 2010) notes that some forms an equal society may require subjects to be required to prove 'shameful' facts about themselves in order that they can be recompensated by society for the factors beyond their control which resulted in their ill health. This therefore forms a critique of luck egalitarianism itself.(Wolff, 2010) For an introduction to luck egalitarianism as applied to health, see (Segall, 2009). This is a valid concern—as the fraught early history of genetics and its links with eugenics highlights.(Buchanan, Brock, Daniels, \& Wikler, 2001) However, in the context of population-wide epidemiological evidence and its application, these concerns may not necessarily materialise: as noted previously, the causal action of socioeconomic, 'intelligence', and genetic propensity on health outcomes is probabilistic. The predictive capacity of epidemiological evidence is typically infeasibly low at the level of the individual—no individual (or discerning observer) can ascertain what factor specifically led to the ill health experienced. Causal reasoning in epidemiological science is at the average or group level, not the individual level (for an overview, see (G. D. Smith, 2011)). At an individual level, the probability of many health conditions may largely by attributable to chance events-yet at a population level, the risk factors investigated may be considered important (probabilistic) causal determinants of health, despite being neither necessary nor sufficient alone in causing any given ill health event.(Rothman \& Greenland, 7 
2005) Further, the focus of relevant public health intervention is also not at the individual level一the focus of interventions to reduce health inequities are widely suggested to be in the form of structural changes to society,(Marmot et al., 2008) with epidemiological monitoring (typically via sampling of cross-sectional and longitudinal datasets) playing a key role in determining if interventions and societal change are successfully narrowing such inequities.(Marmot \& Goldblatt, 2013) Thus, the potential consequences of determining that a given factor is an (average) cause of health inequity is not likely to be directed at a given individual. Stigmatisation or discrimination could result indirectly however, following the dissemination of epidemiological evidence - such is also the case for other risk factors for ill health which are currently widely disseminated as risk factors for many conditions (e.g., including poverty, family history of ill health etc). The usual battery of public defences against stigmatisation and prejudice apply here: public education and the enactment law (e.g., in the UK, the 2010 Equality Act).

The first two components of epidemiological science are to understand the 1) distribution and 2) determinants of population health.(Porta, 2008) Given that these factors are likely to include controversial determinants (such as 'intelligence' and genetic propensities) increasing evidence on these factors is effectively inevitable. As the third component of epidemiological science is widely regarded as the application of this knowledge to improve public health,(Porta, 2008) concerns regarding inadvertent effects should be considered for each possible determinant; there is inherent uncertainty in the potential for adverse consequences. Indeed, even some forms of public health intervention designed to reduce socioeconomic inequalities in health appear to have inadvertently widened such differences—particularly those targeting individuals, in contrast to those which target broader societal structural changes.(Lorenc et al., 2013)

\section{Gaps in current evidence in health inequity research}


A framework to represent the different types of empirical health equity research is shown in Figure 1. Researchers investigate the presence and causal nature of health inequity (Arrow 1), examine their modification across time (ie, is the problem worsening? Arrow 2), and potential amelioration/prevention by intervention (Arrow 3). Further economic and broader societal considerations are then undertaken to appraise the cost-effectiveness of the proposed interventions and their relative utility in the contexts of opportunity costs of investing in other policy areas (Arrow 4). Active lines of research exist across each arrow for SEP_-including for example high profile reports documenting the presence of health disparities,(The Marmot Review Team, 2010) studies investigating their causal nature,(Galama, LlerasMuney, \& van Kippersluis, 2018) change across time (typically descriptively),(Bann, Johnson, Li, Kuh, \& Hardy, 2018; Mackenbach et al., 2014) and potential amelioration by intervention.(Barr, Higgerson, \& Whitehead, 2017; Hu et al., 2016) For each plausible group by which health inequity can be definedsuch as religion, race, area of residence etc — progress across these different aspects of research can be evaluated. For 'intelligence' and genetic-related health determinants, there are large and potentially important gaps to fill.

The causal nature of associations between 'intelligence' and health outcomes remain poorly uncertain,(Deary, Harris, \& Hill, 2018; Hagenaars, Gale, Deary, \& Harris, 2017) and is complicated by apparent shared genetic aetiology of both 'intelligence' and health outcomes.(Arden et al., 2015; Hagenaars et al., 2016) Evidence is also lacking on how 'intelligence'-related disparities in health have changed across time. Notable exceptions include studies of Scandinavian linked data—for example, studies of male Danish conscripts suggested that 'intelligence' and body mass index associations weakened amongst from 1950s to 1980s,(Ehrenstein, Münster, Milstein, Adler, \& Sørensen, 2015) and that inverse associations between 'intelligence' and height have also weakened from the 1940s to 1960s.(Teasdale, Sørensen, \& Owen, 1989) The importance of 'intelligence' for health outcomes may differ depending on the link between 'intelligence' and social outcomes. There is some evidence that 
income and wealth gains in recent decades have been increasingly concentrated amongst those of higher 'intelligence' levels in high income countries (as with other socioemotional skills),(Deming, 2017; Jokela, Pekkarinen, Sarvimäki, Terviö, \& Uusitalo, 2017) potentially leading to a socially disruptive form of societal stratification.(Murray, 2012) The importance of 'intelligence' for social outcomes may increase further in future due to assortative mating — since partners frequently meet in education or work, and the expansion of the digital economy and automation which may further disadvantage those of lower 'intelligence'. The importance of 'intelligence' for education attainment appears to have increased in the UK in the 1990s compared with earlier born cohorts;(Bukodi, Bourne, \& Betthäuser, 2017) given the importance of education attainment for other social outcomes, the result may be that in future decades 'intelligence' is increasingly associated with occupational class, income and wealth. This may lead to a strengthening of causal role of 'intelligence' on health outcomes, given the potential causal impacts of income(Benzeval et al., 2014; Pickett \& Wilkinson, 2015) and wealth(Cesarini, Lindqvist, Östling, \& Wallace, 2016) on some health outcomes. A strengthening causal role may also occur through other mechanisms, for example due to the importance of 'intelligence' in understanding and acting upon the increasing volume and complexity of information encountered by the public related to health. These include food and health literacy(Carbone \& Zoellner, 2012) which are likely important for both health prevention and treatment.

Lack of evidence on change across time is also the case for genetic determinates of health. The suggestion that genetic risk for ill health differs across time is consistent with the considerable unexplained heterogeneity in individual study heritability estimates (eg, for BMI(Elks et al., 2012)), and suggestive evidence from regional studies in the US(Demerath et al., 2013; Rosenquist et al., 2015) or Norway(Brandkvist et al., 2019) that the effects of common genetic variants on BMI have had increasingly larger effects across the later part of the $20^{\text {th }}$ century. In the context of recent health concerns for other outcomes - such as the opioid epidemic in the US,(Case \& Deaton, 2015; Jones et al., 2018) and 
the increasing prevalence of adolescent depression(Collishaw, 2015) - are genetic susceptibilities increasingly important? Without data on genes and and phenotypes amongst different cohorts across time these questions will be hard to answer. Recent years have seen the establishment of large nonrepresentative population studies, such as UK Biobank. While these studies are well utilised to investigate the presence of absence of causal effects, repeated longitudinal and cross-sectional data are required to investigate change in causal effects across time. As in the socioeconomic literature, such efforts will require overcoming multiple methodological challenges involved in estimating whether change is caused by the risk factor investigated, and not other sources of bias (eg, co-occurring declines in response rate(Mindell et al., 2015) leading to selection bias). Reproducing results across multiple data sources is likely to aid such inference regarding change across time.

Finally, for both 'intelligence' and genetics, we lack evidence on the types of interventions which reduce differences in health according to these factors, despite recent acknowledgments that utilising genotype data with interventions may be fruitful (e.g., in order to identify whether genetic factors modify intervention effects).(Plomin \& Haworth, 2010) This is the case for recently derived composites of genetic risk of continuous traits, such as body mass index and depression; in contrast there is longstanding evidence for successful identification and intervention for rarer genetic risks for ill health (eg, phenylketonuria in infancy).(Blau, van Spronsen, \& Levy, 2010) As with the literature on how interventions may affect socioeconomic differences in health, such research is likely challenging since interventions are primarily powered to detect main rather than interactive effects. Pooling and where possible meta-analysing results may therefore aid this research agenda.

\section{Are there other groups of interest in health equity research?}

The fact that differences in health according to 'intelligence' and genetic propensity may be considered forms of health inequity prompts a broader consideration about what other group differences in health 
could and should also be considered health inequities. To modify Teresa May's quote - "the burning injustice that, if you're X, you will die on average Y years earlier than others".

The epidemiological literature has investigated health inequities across multiple groups-including multiple indicators of socioeconomic position, place of residence, race/ethnicity, and religion. To the authors knowledge there is no agreed-upon list of groups which could be defined in terms of health inequities. While the WHO handbook on health inequality monitoring notes multiple 'equity stratifiers' (place of residence, race/ethnicity, occupation, gender, religion, education, socioeconomic status, social capital), these are noted as not being definitive.(World Health Organization, 2013) Each of these groups has variously been investigated according to Figure 1. As with 'intelligence' and genetic-related health differences, there are likely important gaps in knowledge across each group. For example, a recent report notes a lack of evidence regarding health among LGBT adults, particularly those in older age who in younger ages lived whist homosexual sex was illegal in UK law.(Beach, 2019) This may mean that important forms of health inequity are under investigated, and thus under-served by evidence-based policy responses. A systematic review is warranted to help confirm this across multiple domains of inequity. It is also possible — perhaps likely—-there are important health inequities amongst groups which are not yet known, since the group has not yet been identified or investigated. New groups in the population become apparent as they emerge - such as in the founding of new religions (eg, Scientology), or where our understanding of existing groups evolves — such as in the rapidly changing groups related to sexual preference/identity (eg, LGBTQ+) and gender identity (eg, non-binary). Health equity research requires a forward-thinking strategy in order to monitor, understand, and reduce newly discovered forms of health inequity.

Which group difference in health however, should be considered unjust, and to what degree? This requires broader philosophical deliberation. Given that health differences are described according to 
another variable, such differences are often described as being 'bivariate', as opposed to differences in health across all individuals in a population - in which the causes of such dispersion are not explicitly known.(Wolfson \& Rowe, 2001) Ultimately however, the two scenarios are likely linked—a larger variance in some measure of health is likely attributable to some factors, even if not explicitly known; and such factors may in fact be modifiable. In the hypothetical scenario in which the environment is standardised across all members of a given population, variance attributable to genetics will likely increase - if all individuals smoke (to the same degree), then genetic propensities and not smoking status will explain the variance in lung cancer events.(Rose, 2001)

Health differences which are unjust depend, not surprisingly, on the concept of justice employed (for a review of different accounts, see(Ruger, 2004) and(Persad, 2019)). For instance, consistent with Rawls' theory of distributive justice, Daniels et al identifies as unjust health differences as those resulting from the socially controllable factors affecting population health.(Daniels, 2019; Daniels, Kennedy, \& Kawachi, 1999) In accounts of luck egalitarianism as applied to health, a just society is concerned with the factors that shape our lives for which individuals are not responsible;(Segall, 2009) differences in health due to such factors are unjust. What specifically are we are responsible for, however? The scope for health justice seemingly depends upon the extent to which individuals have free will. Clearly we are not responsible for the genes we inherit, yet genes encode our central nervous system and brain, and presumably our capacity to think (as captured, albeit imperfectly, in cognitive tests) - and to make decisions to which we are commonly thought entirely responsible. Behaviours, similar to the seeming majority of all complex human traits examined, are partly heritable.(Polderman et al., 2015) In the absence of free will, the possibilities for group differences in health being judged as unjust seems rather endless - if it is possible to discern the extent to which we do have control over various groups we are considered to be part of, then this may help to delineate which differences in health are particularly unjust. In the absence of this however, a return to the idea of minimising population variance in the health 
outcome — across individuals (rather than in bivariate terms across groups) — may be the most tractable way towards health justice.

Various accounts of health inequity and health justice note the trade-off between minimising health inequities and some other societal good, since public policy resources are finite.(Daniels, 2019; Deaton, 2013; Norheim \& Asada, 2009) These may include the need for technological innovation in medicine and public health, which may ultimately improve the average health level of the population. Norheim and Asada consider distributable justice and its implications for these types of trade-offs, noting that all individuals should have equal health except when "(a) health equality is only possible by making someone less healthy, or (b) there are technological limitations on further health improvement".(Norheim \& Asada, 2009) Daniels recently suggested the need for institutional processes to ensure that such where such trade-offs are made, the decisions and their rationale are made both transparently and with reference to up-to-date evidence.(Daniels, 2019)

The preponderance of groups in health inequity research is arguably partly a manifestation of our human tendency to categorise information. Although grouping is often necessary, it is important to note the limitation of categorisation, particularly where the constructs of interest have meaningful variance beyond the groups identified. This in turn may differ across time. For instance, the highest level of education attainment used in most epidemiological studies is degree or higher; yet the expansion of education has resulted in increasingly large fractions of young people attending universities (50\% in the UK). The relevance variance in this highest category for social outcomes,(Belfield et al., 2019) and potentially health outcomes,(Bann, Hamer, Parsons, Ploubidis, \& Sullivan, 2016) is likely field of study and institution attended. Similarly, for religious affiliation, there is substantial life-altering heterogeneity in beliefs and practices across main religious groups (eg, Christian and Muslim faiths), with different anticipated effects on health outcomes. And yet health equality research(Padela \& Zaidi, 2018) (and 
health inequality monitoring guidelines(NHS England/ Equality and Health Inequalities Team)) typically examine these broad categories. As the groups become smaller, larger sample sizes and optimal sampling strategies are required to provide precise estimates of their health levels. This is particularly so when the at-risk groups are some combination of multiple groups (eg, as notably identified by economists, the increased 'deaths of despair' amongst middle-aged White Americans with low education attainment from 2000-2015(Case \& Deaton, 2017)).

Amidst the uncertainty in quantifying the extent to which group differences in health are unjust, there is benefit in the improvement of both descriptive and causal epidemiological evidence. Doing so will help inform which group differences in health exist, are outside of individuals' control, and are modifiable by societal intervention — all key components in ultimately deciding which differences in health are unjust.

\section{Conclusions}

Research to understand and reduce health inequities are a key components of population health science. The definition of health equity, while commonly thought to apply to socioeconomic-based differences in health, may also apply to other group differences in health, including those caused by 'intelligence' and genetic propensities to ill health. A broader consideration of what constitutes health equity helps highlight the potential modifiability of health differences across multiple forms of disadvantage, and the gaps which future research should address. The extent to which society is just with respect to health can be investigated via a broader range of group differences than commonly considered. Which groups should be considered however requires further empirical and philosophical consideration. 


\section{Acknowledgements}

The author would like to thank the following for providing helpful comments on an earlier version of this draft: Prof Mel Bartley, Dr Vanessa Moulton, Prof Alex Bryson, and Dr Neil Davies.

\section{Funding}

DB is supported by the Economic and Social Research Council (grant number ES/M001660/1) and the Academy of Medical Sciences/the Wellcome Trust "Springboard Health of the public in 2040" Award [HOP001\1025]. Funders had no role in the writing of this article nor the decision to submit it for publication. 


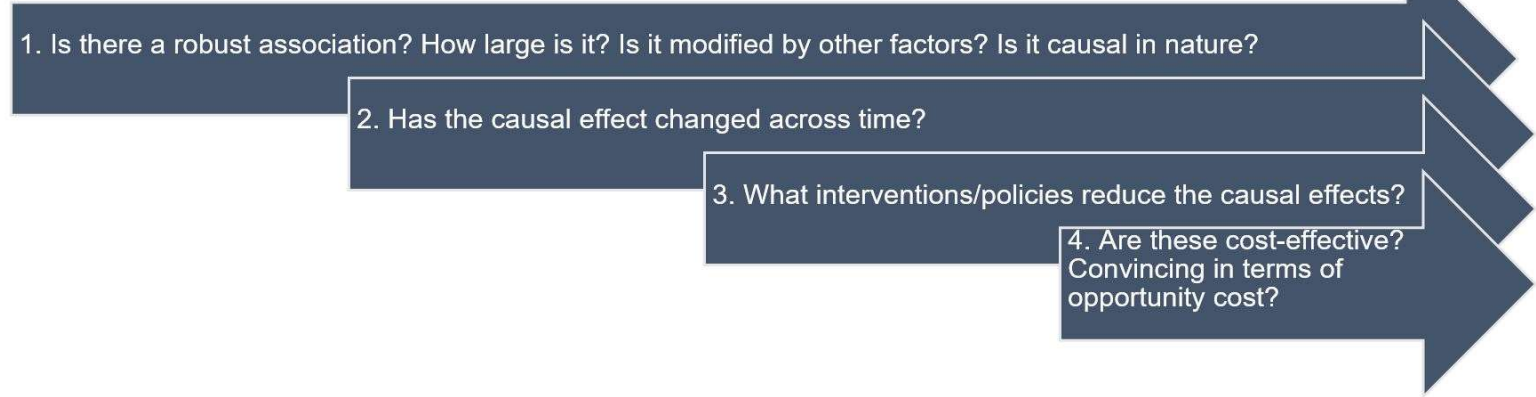

Figure 1. A framework for empirically robust and impactful health inequities research. 
Table 1. Multiple health inequity definitions and their applicability to socioeconomic, 'intelligence', and genetic determinants of health

\begin{tabular}{|l|l|l|l|}
\hline & \multicolumn{2}{|l|}{ Applicable to the following exposures, yes/no } \\
\hline $\begin{array}{l}\text { Health equity/inequity } \\
\text { definition (abridged) }\end{array}$ & $\begin{array}{l}\text { Socioeconomic } \\
\text { position }\end{array}$ & 'Intelligence' & Genetic propensities \\
\hline $\begin{array}{l}\text { Whitehead 1992(Whitehead, } \\
\text { "unnecessary, avoidable, } \\
\text { unfair and unjust" }\end{array}$ & Arguably yes & Arguably yes & Arguably yes \\
\hline $\begin{array}{l}\text { Braveman and Ruskin } \\
\text { 2003(Braveman \& Gruskin, } \\
\text { 2003): } \\
\text { "Health equity is the absence } \\
\text { of systematic disparities in } \\
\text { health (or its social } \\
\text { determinants) between more } \\
\text { and less advantaged social } \\
\text { groups." }\end{array}$ & Arguably yes & $\begin{array}{l}\text { Arguably yes, } \\
\text { assuming in a } \\
\text { complex } \\
\text { society lower } \\
\text { intelligence' } \\
\text { leads to } \\
\text { relative social } \\
\text { disadvantage }\end{array}$ & $\begin{array}{l}\text { Arguably yes, assuming } \\
\text { that genetic propensities } \\
\text { may cause health and social } \\
\text { differences in outcomes } \\
\text { which result in social } \\
\text { disadvantage }\end{array}$ \\
\hline $\begin{array}{l}\text { Porta 2008(Porta, 2008) health } \\
\text { equity: "Fairness and } \\
\text { impartiality in any health } \\
\text { related determinant or } \\
\text { outcome" }\end{array}$ & Arguably yes & Arguably yes & Arguably yes \\
\hline $\begin{array}{l}\text { Norheim and Asada } \\
\text { 2009(Norheim \& Asada, } \\
\text { 2009): every group should } \\
\text { have equal health unless it } \\
\text { makes others less healthy or it } \\
\text { is not possible to improve it }\end{array}$ & Arguably yes & Arguably yes & Arguably yes \\
\hline
\end{tabular}




\section{References}

Adams, J., Mytton, O., White, M., \& Monsivais, P. (2016). Why Are Some Population Interventions for Diet and Obesity More Equitable and Effective Than Others? The Role of Individual Agency. PLoS Medicine, 13(4), e1001990. doi:10.1371/journal.pmed.1001990

Arden, R., Luciano, M., Deary, I. J., Reynolds, C. A., Pedersen, N. L., Plassman, B. L., . . Visscher, P. M. (2015). The association between intelligence and lifespan is mostly genetic. International Journal of Epidemiology, 45(1), 178-185.

Aspara, J., Wittkowski, K., \& Luo, X. (2018). Types of intelligence predict likelihood to get married and stay married: Large-scale empirical evidence for evolutionary theory. Personality and Individual Differences, 122, 1-6.

Bann, D., Hamer, M., Parsons, S., Ploubidis, G. B., \& Sullivan, A. (2016). Does an elite education benefit health? Findings from the 1970 British Cohort Study. International Journal of Epidemiology, 46(1), 293-302.

Bann, D., Johnson, W., Li, L., Kuh, D., \& Hardy, R. (2018). Socioeconomic inequalities in childhood and adolescent body-mass index, weight, and height from 1953 to 2015: an analysis of four longitudinal, observational, British birth cohort studies. The Lancet Public Health.

Barr, B., Higgerson, J., \& Whitehead, M. (2017). Investigating the impact of the English health inequalities strategy: time trend analysis. $B M J, 358, \mathrm{j} 3310$.

Bartley, M. (2016). Health inequality: an introduction to concepts, theories and methods: John Wiley \& Sons.

Batty, G. D., Deary, I. J., \& Gottfredson, L. S. (2007). Premorbid (early life) IQ and later mortality risk: systematic review. Annals of Epidemiology, 17(4), 278-288.

Beach, B. (2019). Raising the equality flag. Health inequalities among older LGBT people in the UK. Retrieved from https://ilcuk.org.uk/wp-content/uploads/2019/05/ILC-Raising-the-equalityflag.pdf:

Belfield, C., Britton, J., Buscha, F., Dearden, L., Dickson, M., van der Erve, L., . . Zhu, Y. (2019). The impact of undergraduate degrees on early-career earnings: Research report: November 2018.

Benzeval, M., Bond, L., Campbell, M., Egan, M., Lorenc, T., Petticrew, M., \& Popham, F. (2014). How does money influence health?

Berkman, L. F., Kawachi, I., \& Glymour, M. M. (2014). Social epidemiology: Oxford University Press.

Blau, N., van Spronsen, F. J., \& Levy, H. L. (2010). Phenylketonuria. The Lancet, 376(9750), 1417-1427.

Brandkvist, M., Bjørngaard, J. H., Ødegård, R. A., Åsvold, B. O., Sund, E. R., \& Vie, G. Å. (2019). Quantifying the impact of genes on body mass index during the obesity epidemic: longitudinal findings from the HUNT Study. BMJ, 366, 14067.

Bratsberg, B., \& Rogeberg, O. (2018). Flynn effect and its reversal are both environmentally caused. Proceedings of the National Academy of Sciences, 115(26), 6674-6678.

Braveman, P., \& Gruskin, S. (2003). Defining equity in health. Journal of Epidemiology and Community Health, 57(4), 254-258.

Buchanan, A., Brock, D. W., Daniels, N., \& Wikler, D. (2001). From chance to choice: Genetics and justice: Cambridge University Press.

Bukodi, E., Bourne, M., \& Betthäuser, B. (2017). Wastage of talent?: Social origins, cognitive ability and educational attainment in Britain. Advances in Life Course Research, 34, 34-42.

Calvin, C. M., Batty, G. D., Der, G., Brett, C. E., Taylor, A., Pattie, A., . . Deary, I. J. (2017). Childhood intelligence in relation to major causes of death in 68 year follow-up: prospective population study. BMJ, 357, j2708. 
Carbone, E. T., \& Zoellner, J. M. (2012). Nutrition and health literacy: a systematic review to inform nutrition research and practice. Journal of the Academy of Nutrition and Dietetics, 112(2), 254265.

Case, A., \& Deaton, A. (2015). Rising morbidity and mortality in midlife among white non-Hispanic Americans in the 21st century. Proceedings of the National Academy of Sciences, 112(49), 15078-15083.

Case, A., \& Deaton, A. (2017). Mortality and morbidity in the 21 st century. Brookings papers on economic activity, 2017, 397.

Cesarini, D., Lindqvist, E., Östling, R., \& Wallace, B. (2016). Wealth, Health, and Child Development: Evidence from Administrative Data on Swedish Lottery Players. The Quarterly Journal of Economics, 131(2), 687-738. Retrieved from http://qje.oxfordjournals.org/content/131/2/687.abstract

Chandola, T., Deary, I. J., Blane, D., \& Batty, G. D. (2006). Childhood IQ in relation to obesity and weight gain in adult life: the National Child Development (1958) Study. International Journal of Obesity, 30(9), 1422.

Collishaw, S. (2015). Annual research review: secular trends in child and adolescent mental health. Journal of Child Psychology and Psychiatry, 56(3), 370-393.

Daniels, N. (2019). Reconciling Two Ethics Goals of Public Health: Reducing Health Disparities and Improving Population Health. In The Oxford Handbook of Public Health Ethics.

Daniels, N., Kennedy, B. P., \& Kawachi, I. (1999). Why justice is good for our health: the social determinants of health inequalities. Daedalus, 128(4), 215-251.

Davies, N. M., Hill, W. D., Anderson, E. L., Sanderson, E., Deary, I. J., \& Smith, G. D. (2019). Multivariable two-sample Mendelian randomization estimates of the effects of intelligence and education on health. Elife, 8 .

Deary, I. J., \& Batty, G. D. (2007). Cognitive epidemiology. Journal of Epidemiology and Community Health, 61(5), 378-384.

Deary, I. J., Harris, S. E., \& Hill, W. D. (2018). What genome-wide association studies reveal about the association between intelligence and physical health, illness, and mortality. Current opinion in psychology.

Deary, I. J., \& Johnson, W. (2010). Intelligence and education: causal perceptions drive analytic processes and therefore conclusions. International Journal of Epidemiology, 39(5), 1362-1369.

Deary, I. J., Strand, S., Smith, P., \& Fernandes, C. (2007). Intelligence and educational achievement. Intelligence, 35(1), 13-21.

Deaton, A. (2013). What does the empirical evidence tell us about the injustice of health inequalities. Inequalities in health: concepts measures, and ethics, 263, 281.

Demerath, E. W., Choh, A. C., Johnson, W., Curran, J. E., Lee, M., Bellis, C., . . Towne, B. (2013). The positive association of obesity variants with adulthood adiposity strengthens over an 80-year period: a gene-by-birth year interaction. Human Heredity, 75(2-4), 175-185.

Deming, D. J. (2017). The growing importance of social skills in the labor market. The Quarterly Journal of Economics, 132(4), 1593-1640.

Ding, W., Lehrer, S. F., Rosenquist, J. N., \& Audrain-McGovern, J. (2009). The impact of poor health on academic performance: New evidence using genetic markers. Journal of Health Economics, 28(3), 578-597.

Downs, J. S., \& Loewenstein, G. (2011). Behavioral economics and obesity. In The Oxford handbook of the social science of obesity.

Edenberg, H. J., \& Foroud, T. (2013). Genetics and alcoholism. Nature reviews Gastroenterology \& hepatology, 10(8), 487.

Ehrenstein, V., Münster, A. M. B., Milstein, A., Adler, N. E., \& Sørensen, H. T. (2015). Body mass index and cognitive function: birth cohort effects in young men. Obesity, 23(5), 931-934. 
Elks, C. E., Den Hoed, M., Zhao, J. H., Sharp, S. J., Wareham, N. J., Loos, R. J., \& Ong, K. K. (2012). Variability in the heritability of body mass index: a systematic review and meta-regression. Frontiers in Endocrinology, 3, 29.

Fletcher, J. M., \& Lehrer, S. F. (2009). The effects of adolescent health on educational outcomes: Causal evidence using genetic lotteries between siblings. Paper presented at the Forum for Health Economics \& Policy.

Galama, T. J., Lleras-Muney, A., \& van Kippersluis, H. (2018). The Effect of Education on Health and Mortality: A Review of Experimental and Quasi-Experimental Evidence. National Bureau of Economic Research.

Hagenaars, S. P., Gale, C. R., Deary, I. J., \& Harris, S. E. (2017). Cognitive ability and physical health: a Mendelian randomization study. Scientific Reports, 7(1), 2651.

Hagenaars, S. P., Harris, S. E., Davies, G., Hill, W. D., Liewald, D. C., Ritchie, S. J., . . Malik, R. (2016). Shared genetic aetiology between cognitive functions and physical and mental health in UK Biobank (N=112 151) and 24 GWAS consortia. Molecular Psychiatry, 21(11), 1624.

Howe, L. D., Kanayalal, R., Beaumont, R., Davies, A. R., Frayling, T. M., Harrison, S., . . . Tyrrell, J. (2019). Effects of body mass index on relationship status, social contact, and socioeconomic position: Mendelian Randomization study in UK Biobank. BioRxiv, 524488.

Hu, Y., van Lenthe, F. J., Judge, K., Lahelma, E., Costa, G., de Gelder, R., \& Mackenbach, J. P. (2016). Did the English strategy reduce inequalities in health? A difference-in-difference analysis comparing England with three other European countries. BMC Public Health, 16(1), 865.

Jokela, M., Pekkarinen, T., Sarvimäki, M., Terviö, M., \& Uusitalo, R. (2017). Secular rise in economically valuable personality traits. Proceedings of the National Academy of Sciences, 114(25), 6527-6532.

Jones, M. R., Viswanath, O., Peck, J., Kaye, A. D., Gill, J. S., \& Simopoulos, T. T. (2018). A brief history of the opioid epidemic and strategies for pain medicine. Pain and therapy, 7(1), 13-21.

Kaprio, J. (2000). Genetic epidemiology. BMJ, 320(7244), 1257. doi:10.1136/bmj.320.7244.1257

Khera, A. V., Chaffin, M., Wade, K. H., Zahid, S., Brancale, J., Xia, R., . . Bick, A. (2019). Polygenic prediction of weight and obesity trajectories from birth to adulthood. Cell, 177(3), 587-596. e589.

Lawlor, D., Clark, H., Smith, G. D., \& Leon, D. (2006). Childhood intelligence, educational attainment and adult body mass index: findings from a prospective cohort and within sibling-pairs analysis. International Journal of Obesity, 30(12), 1758.

Lorenc, T., Petticrew, M., Welch, V., \& Tugwell, P. (2013). What types of interventions generate inequalities? Evidence from systematic reviews. Journal of Epidemiology and Community Health, 67(2), 190-193. Retrieved from http://jech.bmj.com/content/67/2/190.abstract

Mackenbach, J. P., Kulhánová, I., Menvielle, G., Bopp, M., Borrell, C., Costa, G., . . . Lundberg, O. (2014). Trends in inequalities in premature mortality: a study of 3.2 million deaths in 13 European countries. Journal of Epidemiology and Community Health, 69, 207-217. Retrieved from http://jech.bmj.com/content/early/2014/06/25/jech-2014-204319.abstract

Marks, G. N. (2013). Education, social background and cognitive ability: The decline of the social: Routledge.

Marmot, M. (2015). The health gap: the challenge of an unequal world: Bloomsbury Publishing USA.

Marmot, M. (2017). Social justice, epidemiology and health inequalities. European Journal of Epidemiology, 32(7), 537-546.

Marmot, M., Allen, J., Bell, R., Bloomer, E., \& Goldblatt, P. (2012). WHO European review of social determinants of health and the health divide. The Lancet, 380(9846), 1011-1029. Retrieved from http://www.sciencedirect.com/science/article/pii/S0140673612612288

Marmot, M., Friel, S., Bell, R., Houweling, T. A., Taylor, S., \& Health, C. o. S. D. o. (2008). Closing the gap in a generation: health equity through action on the social determinants of health. The Lancet, 372(9650), 1661-1669.

Marmot, M., \& Goldblatt, P. (2013). Importance of monitoring health inequalities. BMJ. 
Mindell, J., Giampaoli, S., Goesswald, A., Kamtsiuris, P., Mann, C., Mannisto, S., . . Group, o. b. o. t. H. R. R. (2015). Sample selection, recruitment and participation rates in health examination surveys in Europe - experience from seven national surveys. BMC Medical Research Methodology, 15(1), 78. Retrieved from http://www.biomedcentral.com/1471-2288/15/78

Murray, C. (2012). Coming apart: The state of white America, 1960-2010: Crown Forum.

NHS England/ Equality and Health Inequalities Team. Monitoring Equality and Health Inequalities: A Position Paper. Retrieved from https://www.england.nhs.uk/wpcontent/uploads/2015/03/monitrg-ehi-pos-paper.pdf:

Norheim, O. F., \& Asada, Y. (2009). The ideal of equal health revisited: definitions and measures of inequity in health should be better integrated with theories of distributive justice. International Journal for Equity in Health, 8(1), 40.

Organization, W. H. (2004). Commission on social determinants of health: World Health Organization, Executive Board.

Padela, A. I., \& Zaidi, D. (2018). The Islamic tradition and health inequities: A preliminary conceptual model based on a systematic literature review of Muslim health-care disparities. Avicenna journal of medicine, $8(1), 1$.

Persad, G. (2019). Justice and public health. The Oxford Handbook of Public Health Ethics, 33.

Pickett, K. E., \& Wilkinson, R. G. (2015). Income inequality and health: a causal review. Social Science and Medicine, 128, 316-326.

Plomin, R. (2018). Blueprint: How DNA makes us who we are: MIT Press.

Plomin, R., \& Deary, I. J. (2015). Genetics and intelligence differences: five special findings. Molecular Psychiatry, 20(1), 98.

Plomin, R., \& Haworth, C. M. (2010). Genetics and intervention research. Perspectives on Psychological Science, 5(5), 557-563.

Polderman, T. J., Benyamin, B., De Leeuw, C. A., Sullivan, P. F., Van Bochoven, A., Visscher, P. M., \& Posthuma, D. (2015). Meta-analysis of the heritability of human traits based on fifty years of twin studies. Nature Genetics, 47(7), 702.

Porta, M. (2008). A dictionary of epidemiology. Oxford, UK: Oxford University Press.

Protzko, J. (2015). The environment in raising early intelligence: A meta-analysis of the fadeout effect. Intelligence, 53, 202-210.

Radnitz, C., Loeb, K. L., DiMatteo, J., Keller, K. L., Zucker, N., \& Schwartz, M. B. (2013). Optimal defaults in the prevention of pediatric obesity: from platform to practice. Journal of food $\&$ nutritional disorders, 2(5), 1.

Ritchie, S. J., \& Tucker-Drob, E. M. (2018). How much does education improve intelligence? A metaanalysis. Psychological Science, 29(8), 1358-1369.

Rose, G. (2001). Sick individuals and sick populations. International Journal of Epidemiology, 30(3), 427-432.

Rosenblad, A., Nilsson, G., \& Leppert, J. (2012). Intelligence level in late adolescence is inversely associated with BMI change during 22 years of follow-up: results from the WICTORY study. European Journal of Epidemiology, 27(8), 647-655.

Rosenquist, J. N., Lehrer, S. F., O’Malley, A. J., Zaslavsky, A. M., Smoller, J. W., \& Christakis, N. A. (2015). Cohort of birth modifies the association between FTO genotype and BMI. Proceedings of the National Academy of Sciences, 112(2), 354-359.

Rothman, K. J., \& Greenland, S. (2005). Causation and causal inference in epidemiology. American Journal of Public Health, 95(S1), S144-S150.

Ruger, J. P. (2004). Ethics of the social determinants of health. The Lancet, 364(9439), 1092-1097.

Sala, G., \& Gobet, F. (2018). Cognitive training does not enhance general cognition. Trends in Cognitive Sciences.

Segall, S. (2009). Health, luck, and justice: Princeton University Press. 
Smith, E., Hay, P., Campbell, L., \& Trollor, J. N. (2011). A review of the association between obesity and cognitive function across the lifespan: implications for novel approaches to prevention and treatment. Obesity Reviews, 12(9), 740-755.

Smith, G. D. (2011). Epidemiology, epigenetics and the 'Gloomy Prospect': embracing randomness in population health research and practice. International Journal of Epidemiology, 40(3), 537-562.

Strenze, T. (2007). Intelligence and socioeconomic success: A meta-analytic review of longitudinal research. Intelligence, 35(5), 401-426.

Teasdale, T. W., Sørensen, T., \& Owen, D. R. (1989). Fall in association of height with intelligence and educational level. BMJ: British Medical Journal, 298(6683), 1292.

The Marmot Review Team. (2010). Fair Society, Healthy Lives. Retrieved from

Ttofi, M. M., Farrington, D. P., Piquero, A. R., Lösel, F., DeLisi, M., \& Murray, J. (2016). Intelligence as a protective factor against offending: A meta-analytic review of prospective longitudinal studies. Journal of Criminal Justice, 45, 4-18.

Turkheimer, E. (2011). Genetics and human agency: comment on Dar-Nimrod and Heine (2011). Psychological Bulletin.

Turkheimer, E. (2019). The Social Science Blues. Hastings Center Report.

Tyrrell, J., Jones, S. E., Beaumont, R., Astley, C. M., Lovell, R., Yaghootkar, H., . . Frayling, T. M. (2016). Height, body mass index, and socioeconomic status: mendelian randomisation study in UK Biobank. BMJ, 352. Retrieved from http://www.bmj.com/content/352/bmj.i582.abstract

Wester, G. (2018). When Are Health Inequalities Unfair? Public Health Ethics, 11(3), 346-355.

Whitehead, M. (1991). The concepts and principles of equity and health. Health Promotion International, $6(3), 217-228$

Wolff, J. (1998). Fairness, respect, and the egalitarian ethos. Philosophy \& public affairs, 27(2), 97-122.

Wolff, J. (2010). Fairness, respect and the egalitarian ethos revisited. The Journal of Ethics, 14(3-4), 335350.

Wolfson, M., \& Rowe, G. (2001). On measuring inequalities in health. Bulletin of the World Health Organization, 79, 553-560.

World Health Organization. (2013). Handbook on health inequality monitoring: with a special focus on low-and middle-income countries: World Health Organization.

Wraw, C., Deary, I. J., Der, G., \& Gale, C. R. (2018). Maternal and offspring intelligence in relation to BMI across childhood and adolescence. International Journal of Obesity, 1.

Zax, J. S., \& Rees, D. I. (2002). IQ, academic performance, environment, and earnings. Review of Economics and Statistics, 84(4), 600-616. 